\title{
Development and implementation of a monitoring and information system to increase water use efficiency in arid and semi-arid areas in Limarí, Central Chile (WEIN)
}

\author{
Erich Berger, David Balmert, and Jürgen Richter \\ ribeka GmbH, 53332 Bornheim, Germany \\ Correspondence to: Erich Berger (berger@ribeka.com)
}

Published: 17 October 2016

\begin{abstract}
The project WEIN was funded by the Federal Ministry of Education and Research (BMBF I Berlin, Germany) in the framework of the high-tech strategy of Germany's program "KMU-Innovativ". The project started in 2012 and was completed in 2014. In the scope of the project, an integrated system for analysis, monitoring and information at river basin level was developed, which provides relevant information for all stakeholders that are concerned with water resource issues. The main objective of the project was to improve water use efficiency and hence ensure the agricultural production in the region. The pilot region, in which this system was implemented, is the semi-arid Limarí basin in Northern Central Chile. One of the main parts of the project was the development and implementation of a web- and app-based irrigation water ordering and accounting system for local farmers.
\end{abstract}

\section{Introduction}

The growing world population, the rapidly increasing demand for high quality food and for water for agriculture use, the need to secure the provision of drinking water demands innovative and holistic solutions and products to increase the water use efficiency. These solutions are especially required in arid and semi-arid areas. Additional factors such as economic development, population growth and climate change deteriorate the situation. Therefore the long term, sustainable resource management at river basin level requires a complete, standardized and for all staff members operable management system. In the framework of the project WEIN a complex management system for water resources in the semi-arid region Limarí, Central Chile, was developed and implemented.

The aim of the project was to optimize usage of the scarce water resources subsequently to ensure the agricultural production.

The project was carried out in collaboration with SEBA Hydrometrie GmbH, ITT (TH Köln) and the local Chilean partners ULS (University La Serena, Chile) and CEAZA (Centro de Estudios Avanzados en Zonas Aridas, La Serena, Chile).

\section{The project region: Limarí basin, Central Chile}

The Limarí basin is located in the northern semi-arid region of Coquimbo (IV.) (Fig. 1). The Limarí catchment area covers about 1.3 million ha, where of 65000 ha are used for agricultural production (INE, 2007). Despite the little amount of annual precipitation (average $146 \mathrm{~mm}$ p.a.) there is a lot of agricultural land use (Oyarzun, 2010). Because of this little average rainfall, the agricultural production is strongly dependent on the hydro-geological processes and the snow melt in the Andes. Therefore, this region is prone to the impact of the global warming, since the increased glacial melting and reduced snowfall will reduce the discharge from the mountains in the summer (Barnett et al., 2005). This could lead to an increasing number of droughts (Young et al., 2010). To catch up with all these factors, an efficient water management is indispensable. Figure 1 shows the Limarí river basin including main rivers, the reservoirs and the irrigation area alongside the Limarí. 


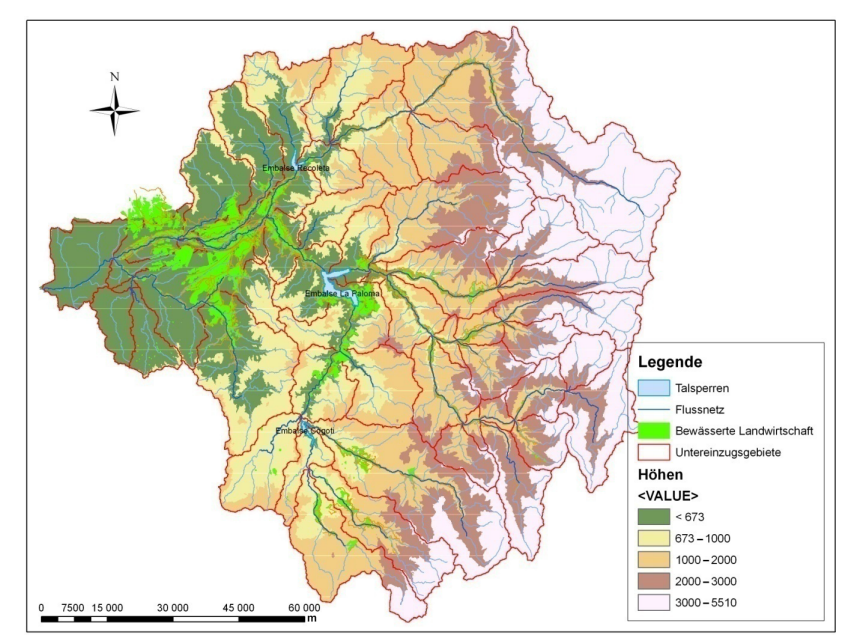

Figure 1. Limarí river basin (created by Kretschmer, 2011).

\section{The monitoring and information system}

The information and management system developed during the WEIN project consists on the one hand of the installed optimized SEBA sensor systems which measure relevant climate and water run off data, and on the other hand of the modular software system based on the ribeka water resource management system GW-Base.

All water used for irrigation purposes is distributed and managed in a complex reservoir and channel system. The water either derives directly from the local rivers (e.g. the Limarí) or from different reservoirs (e.g. Embalse la Paloma, Embalse Recoleta) which are dependent on the annual runoff due to the snowmelt. The Water distribution is managed by different water associations, each responsible for a channel system deriving from a reservoir or a certain river section. All local Farmers possess water rights which allow them to order corresponding water amounts from the responsible association. The farmers are entitled to certain water annual irrigation water quotas which are recalculated every year depending of the annual water availability. Hence, in addition to the water monitoring system a management system for water resources and the farmer's water rights (and corresponding irrigation water quotas) was developed and implemented. Orders for irrigation quotas are sent via smartphones by the farmers are automatically processed and carried out (Fig. 3). All relevant data (measurements, monitoring data, irrigation quotes) are automatically deployed and processed in the modular software system based on resource management system GW-BASE. Individual software modules were customized for these special usage scenarios and applications (e.g. water authorities, farmers, irrigation associations). For the first time, a monitoring and management system is available, which provides the possibility to use all relevant data for an integrated water management. The com- munication scheme and interaction of all results in the newly developed WEIN system are shown in Figs. 2 and 4.

\subsection{The monitoring system}

To account the available resources holistically, an extensive, continuous collection of the relevant data is needed. The innovative and customized sensor technology ensures this. The surface water and irrigation channels are monitored by newly developed, robust and cost-effective water flow and water level sensors. Rainfall and the lack of infrastructure - especially in the mountain region of the Andes - require a special adaptation of the installed sensors. Beside the problem of data transmission, rainfall and snowfall sensors have to work without an external power supply. The development of an energy-efficient and maintenance-free sensor combination which stands the rough climate conditions was needed.

All relevant pre-existing data concerning the Limarí basin was researched and imported to GW-Base and GW-Web. This data formed the basis for the whole monitoring system and is available for all project partners.

The water availability is quantified on the basis of climate and water runoff data. On irrigation system level, the channel outflow and reservoirs levels are measured continuously, in order to estimate water consumption and water losses due to leakage and evaporation. The estimation of future water availability and demand is carried out by an integrated review of the measurement results, historical hydro-meteorological and socio-economic data in combination with customized hydrological models.

The monitored data includes environmental parameters like precipitation and evaporation, water levels and quantities like discharge and runoff, as well as water quality parameters. All monitored data was imported to the GW-Base database.

\subsection{The information and management system}

To account the available resources holistically, an extensive, continuous collection of the relevant data is needed. The innovative and customized sensor technology ensures this. The surface water and irrigation channels are monitored by newly developed, robust and cost-effective water flow and water level sensors. Rainfall and the lack of infrastructure - especially in the mountain region of the Andes - require a special adaptation of the installed sensors. Beside the problem of data transmission, rainfall and snowfall sensors have to work without an external power supply. The development of an energy-efficient and maintenance-free sensor combination which stands the rough climate conditions was needed.

All relevant pre-existing data concerning the Limarí basin was researched and imported to GW-Base and GW-Web. This data formed the basis for the whole monitoring system and is available for all project partners. 


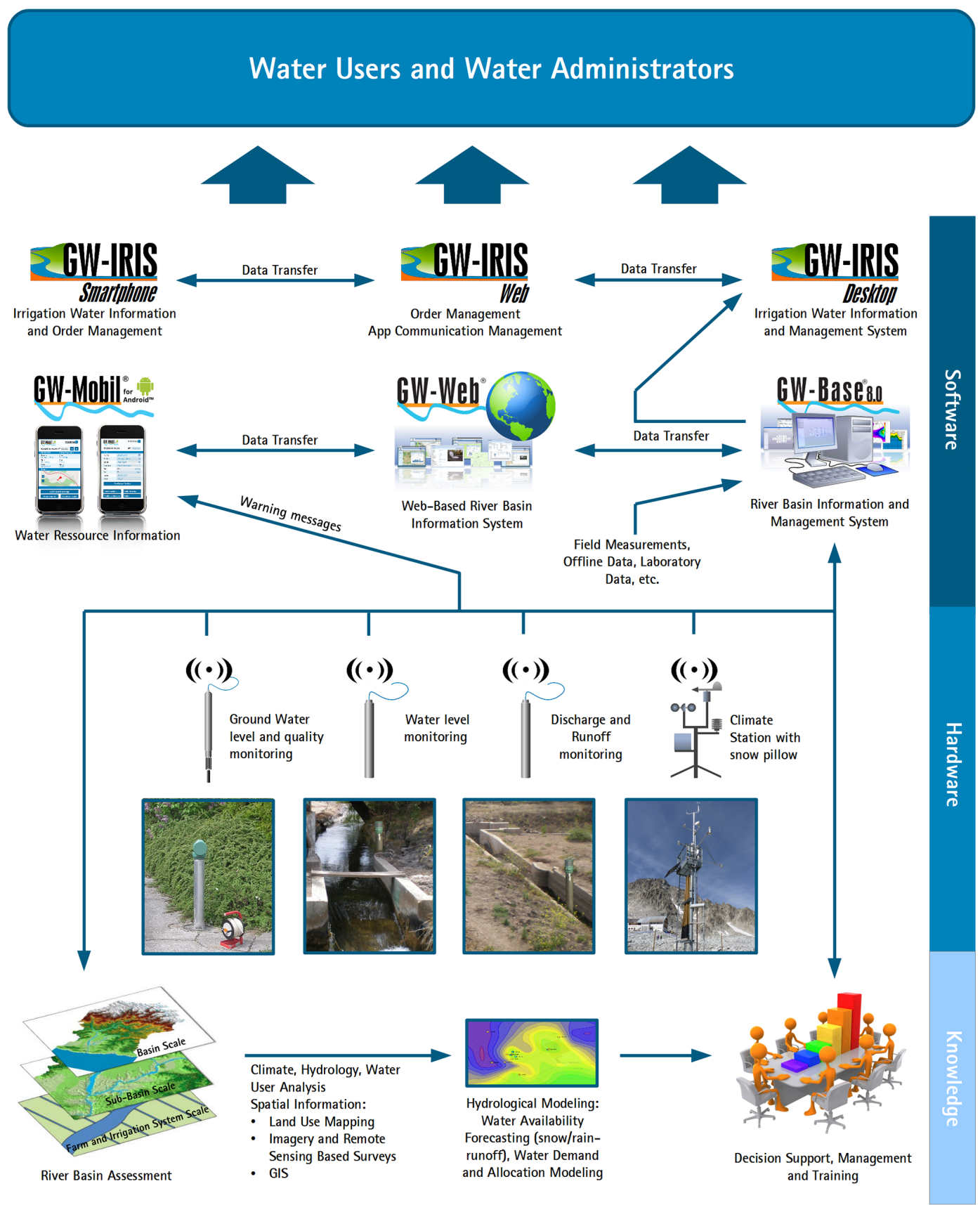

Figure 2. Communication scheme of the complete, newly developed WEIN system.

The water availability is quantified on the basis of climate and water runoff data. On irrigation system level, the channel outflow and reservoirs levels are measured continuously, in order to estimate water consumption and water losses due to leakage and evaporation. The estimation of future water availability and demand is carried out by an integrated review of the measurement results, historical hydro-meteorological and socio-economic data in combination with customized hydrological models.
The monitored data include environmental parameters like precipitation and evaporation, water levels and quantities like discharge and runoff, as well as water quality parameters. All monitored data was imported to the GW-Base database.

\section{Conclusions}

An integrated system for analysis, monitoring, information and resource management at river basin level, which allows efficient and demand-oriented irrigation water management, 


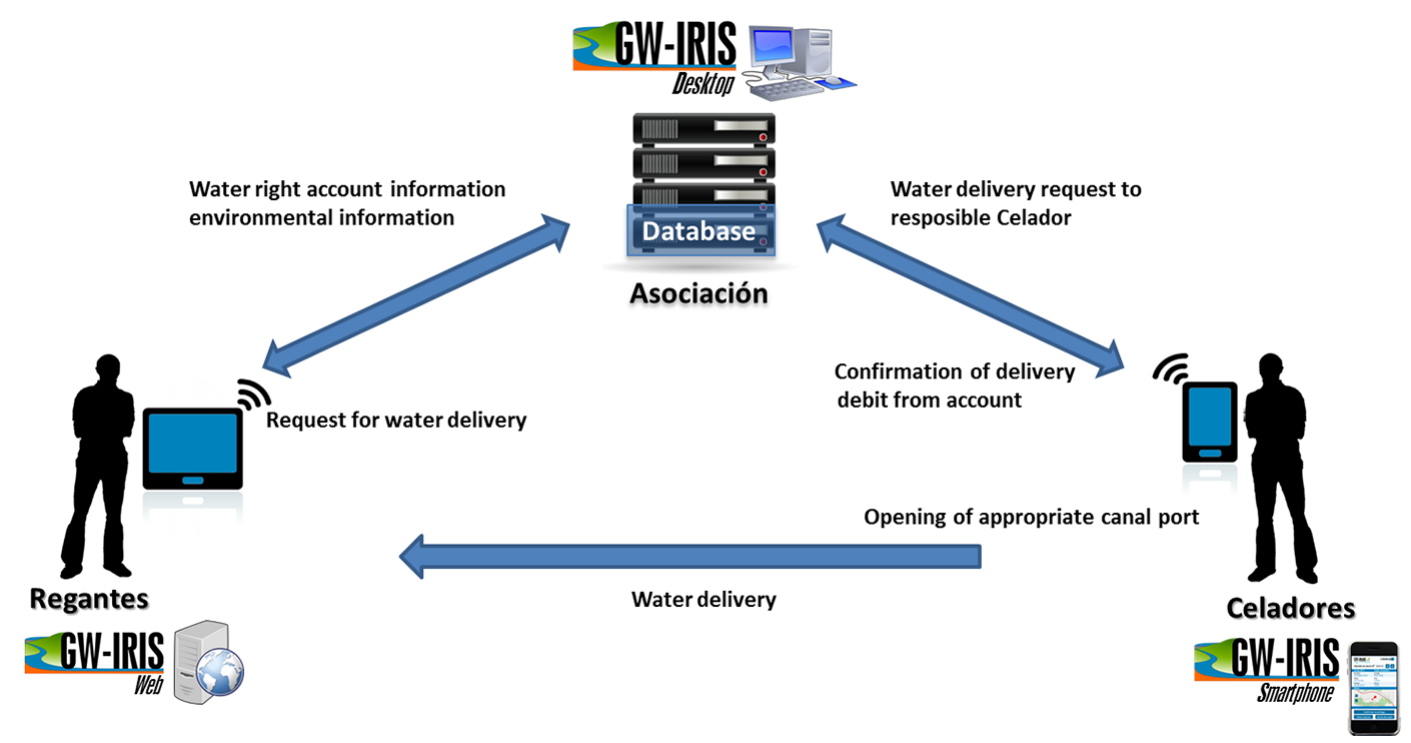

Figure 3. GW-IRIS communication scheme.

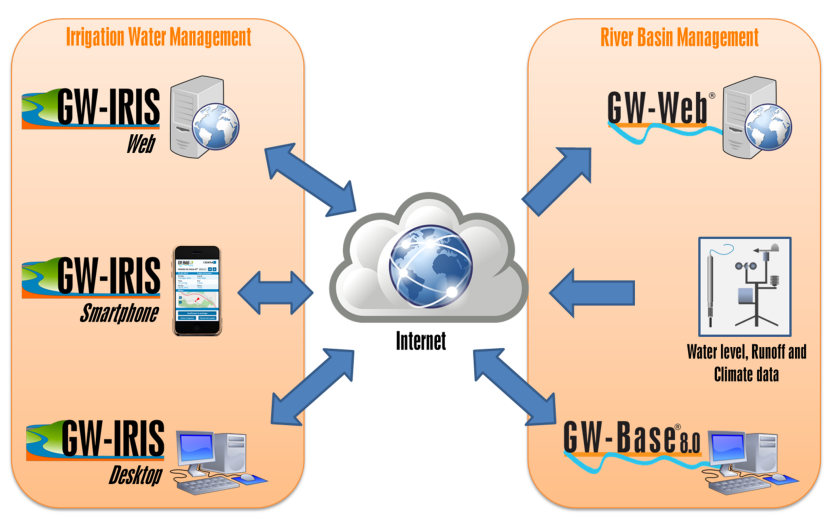

Figure 4. The complete software system. Communication scheme of the water monitoring and management system GW-Base and the newly developed irrigation administration system GW-IRIS.

is an essential tool for all concerned stakeholders. The system is a substantial contribution to increase water use efficiency in the Limarí region and therefore is able to ensure the agricultural production.

For the first time, a monitoring and management system is available, which provides the possibility to use all relevant data for an integrated water management. The worldwide demand for water will increase rapidly because of the growing world population and climatic changes. This collaborative product development ideally fits to this increasing demand.

\section{Data availability}

Additional research information can be found at:

- BMBF (Bundesministerium für Bildung und Forschung): www.bmbf.de, www.foerderportal.bund.de

- ribeka GmbH: www.ribeka.com

- Official Project Website: www.hidro-limari.info/

Acknowledgements. The WEIN project was funded by the Federal Ministry of Education and Research (BMBF, Berlin, Germany) in the framework of the high-tech strategy of Germany's program "KMU-Innovativ" (funding/project number: 02WQ1256A).

\section{References}

Barnett, T. P., Adam, J. C., and Lettenmaier, D. P.: Potential impacts of a warming climate on water availability in snow-dominated regions, Nature, 438, 303-309, 2005.

INE: Censo Agropecuario: http://www.inecoquimbo.cl (last access: 18 April 2011), 2007.

Oyarzun, R.: Estudio de caso: Cuenca del Limarí, Región de Coquimbo, Chile, Compilación Resumida de Antecedentes, Centro de Estudios Avanzados en Zonas Aridas, La Serena, Universidad de la Serena, 2010.

Young, G., Zavala H., Wandel, J., Smit B., Salas, S., Jimenez, E., Fiebig, E., Espinoza, R., Diaz, H., and Cepeda, J.: Vulnerability and adaptation in a dryland community of the Elqui Valley, Chile, Climatic Change, 98, 245-276, 2010. 